\title{
Mitral Valve Replacement in Patients with Extreme Pulmonary Hypertension: Tertiary Center Experience of 680 Cases
}

\author{
Mohamed Alassal ${ }^{1,2 *}$, Moataz Rezk $^{1}$, Ehab Fawzy ${ }^{1}$, Ashraf Elnahas ${ }^{1}$, Basem Mofreh ${ }^{1}$, Ahmed Sobhy ${ }^{1}$, Hany
} Osman ${ }^{3}$, Mohamed Saffan ${ }^{1}$, Hany Ebaid ${ }^{4}$, Ayman Ghoneim ${ }^{4,5}$ and Mahmoud Elemam ${ }^{1}$

${ }^{1}$ Cardiothoracic Surgery Department, Benha University Hospitals, Egypt

${ }^{2}$ PAAMCC, Saudi Arabia

${ }^{3}$ Cardiothoracic Surgery Department, Damanhour National Medical Institute, Egypt

${ }^{4}$ Cardiothoracic Surgery Department, Alazhar University, Egypt

${ }^{5}$ Almoasa Specialist Hospital, Alhasa, KSA

Submission: January 02, 2018; Published: January 31, 2018

*Corresponding author: Mohamed Alassal, Cardiothoracic Surgery Department, Faculty of Medicine, Benha University Hospitals, Egypt, Email: dmohamedabdelwahab@gmail.com

\section{Abstract}

Many forms of left-sided heart disease can be associated with pulmonary hypertension (PH-LHD) which typically indicates more advanced heart disease, more severe symptoms and worse prognosis. Mitral valve disease, both insufficiency and stenosis, can lead to the downstream development of PH. Current guidelines suggest that the most effective therapy for severe mitral valve disease (stenosis and/or regurgitation) is surgical intervention, yet in some cases, the operative outcome bordered by high perioperative risks. Patients and methods: Data for this study included 680 cases of adult patients underwent first-time mitral valve replacement. All patients of the study were divided into 2 groups: those who had PASP $50-80 \mathrm{mmHg}$ categorized as severe pulmonary hypertension=(group I) and those who had PASP above $80 \mathrm{mmHg}$ Categorized as extreme $\mathrm{PH}=($ group II).

Results: Echo-cardio graphic data revealed that $60.3 \%$ (410/680) of patients had signs of mitral stenosis, 25\% (170/680) had mitral regurgitation while 14.7\% (100/680) had double mitral valve pathology (MS and MR). 76 patients (11.2\%) had less than moderate TR, 132 (19.4\%) had moderate TR and 472 (69.4\%) had severe TR. Most of mortality in both groups occurs during the first post-operative week and occurred due to hemodynamic instability and acute heart failure. It was $3.7 \%(20 / 540)$ in group I and $14.3 \%(20 / 140)$ in group II with a marked rise in this rate between patients of group II ( $p=0.03) .12$ cases out of the $20(60 \%)$ of mortality of group I were above fifty years old and 16 cases out of the 20 cases of mortality of group II ( $80 \%$ ) were above fifty years old and the statistical analysis revealed that increased age with the severity of pulmonary hypertension increase the rate of mortality $(\mathrm{p}=0.031)$.

Conclusion: Early referral of cases of mitral valve disease with PHT to surgery once indicated to avoid increased operative risk secondary to long standing PHT. Mitral valve replacement (MVR) with severe PHT could be done with less risk when surgery offered at proper time with management strategy to avoid pulmonary hypertensive events.

Keywords: Rheumatic valve disease; Mitral stenosis; Pulmonary hypertension; Left sided heart disease

\section{Introduction}

In developing countries like in our country "Egypt"; rheumatic fever and rheumatic heart disease are bigger problems than ever. It was estimated recently that worldwide 15.6 million people have rheumatic heart disease and that there are 470,000 new cases of rheumatic fever and 233,000 deaths attributable to rheumatic fever or rheumatic heart disease each year. The actual numbers are likely to be higher in developing countries because almost all these numbers and statistics come from developing countries [1]. Many forms of left-sided heart disease can be associated with pulmonary hypertension (PH-LHD) which typically indicates more advanced heart disease, more severe symptoms and worse prognosis [2,3].

Pulmonary hypertension (PH) due to left-sided heart disease (LHD), classified by the World Health Organization as Group 2 (WHO 2), is secondary to left ventricular (LV) systolic dysfunction, LV diastolic dysfunction, or valvular heart disease (VHD) [4]. The principle insult in this class of $\mathrm{PH}$ is elevated left ventricular end diastolic pressure (LVEDP and/or left atrial pressures), which is transmitted to the pulmonary vasculature, raising pulmonary artery pressure [5]. Mitral valve disease, both insufficiency and stenosis, can lead to the downstream development of PH. Elevated 
PAP has long been recognized as a complication of mitral stenosis (MS) [6]. In mitral regurgitation it is dependent on the valvular abnormality and chronicity. Barbieri et al. [7] demonstrated that degenerative MR due to a flail leaflet causes $\mathrm{PH}$ at baseline in $23 \%$ of patients.

Exaggerated PH can have a variety of mechanisms and comorbidities, particularly in the aging population. Most often, this is due to long-standing pulmonary venous hypertension causing significant vascular re-modeling and decreased pulmonary circulation compliance [6]. Current guidelines suggest that the most effective therapy for severe mitral valve disease (stenosis and/or regurgitation) is surgical intervention, yet in some cases, the operative outcome bordered by high perioperative risks [8]. Pulmonary hypertension (PHT) has been considered a mortality risk factor in cardiac surgical patients found in $15-60 \%$ of patients who have mitral valve disease. Longstanding PHT increases the after load on the right ventricle, leading to hypertrophy and eventually, core-pulmonale [9].

The development of PH is often an indication for mitral valve (MV) or atrioventricular (AV) intervention, but has also been well documented to be a procedural risk factor [10]. Guideline-directed pharmacologic treatment for the underlying heart failure with reduced $\mathrm{EF}$ (HFrEF) and heart failure with preserved $\mathrm{EF}$ (HFpEF): diuretics, vasodilators, and neuro-hormonal antagonists. In addition, patients should be considered for mechanical support and resynchronization therapy when appropriate. Targeted therapies for PH-LHD are lacking, showing only limited benefit in symptomatic improvement without affecting clinical survival [11]. In developing countries, even young patients can present with a very advanced stage of valvular heart disease. The life expectancy of these patients is much lower than the national average. Almost negligible information is available from developing countries [6]. All the major studies are from the developed world. In the absence of perfect data, we will build our case using available evidence. The aim of our study is to find a strategy to improve outcome after mitral valve replacement in patients with severe and extreme PHT in our country.

\section{Patients and Methods}

Data for this study were obtained from the patients' medical records in Banha University Hospital and Damanhour national medical institute in (Egypt) and in PAAMCC cardiac center in (Saudi Arabia) others during the period (Jan 2010 to Dec 2016) and included 680 cases of adult patients underwent first-time mitral valve replacement. Patients with multi-valvular diseases were excluded as well as patients with ischemic heart diseases and $\backslash$ or past history of open heart surgeries.

All patients of the study were divided into 2 groups: those who had PASP $50-80 \mathrm{mmHg}$ categorized as severe pulmonary hypertension=(group I) and those who had PASP above $80 \mathrm{mmHg}$ Categorized as extreme $\mathrm{PH}=$ (group II). PASP values were obtained from Doppler echocardiography or Right heart catheter and calculated using the modified Bernoulli equation $4 \mathrm{x}$ [tricuspid regurgitation jet velocity] ${ }^{2}+$ right atrial pressure) [9]. All patients of both groups were given sildenafil in a dose of $0.5 \mathrm{mg} /$ $\mathrm{kg}$ single dose in the morning of surgery ( $2 \mathrm{hs}$ before induction of anesthesia). During operative procedure we start to give all patients milrinone at a dose of $50 \mathrm{mcg} / \mathrm{kg}$ loading over 10 minutes then $0.375-0.75 \mathrm{mcg} / \mathrm{Kg} / \mathrm{min}$ IV infusion before coming off bypass.

During the procedure all patients started anesthetic process, cannulation and conduction of bypass, surgical procedure in the form of mitral valve replacement with tricuspid valve repair for cases with moderate and severe TR, weaning from heart-lung machine and patient transfer to the intensive care unit. Total bypass time and aortic cross clamp time was calculated in the two groups. We have used hemo-filter for all cases from the beginning of bypass, with total fluid balance calculation. PASP was measured post-operatively, one month, three months and six months postoperatively.

\section{Statistical Analysis}

Data were collected and compared afterward. The information was entered in a computer-designed format to facilitate analysis by using the SPSS 9.0 statistical program for Windows. Quantitative variables were expressed as mean \pm standard deviation (SD). Difference before and after the mitral valve replacement were evaluated. The significance of the differences was calculated by Wilcoxon test for the paired groupings. The results from group II were compared with those from group I. Analysis was carried out by the $\chi^{2}$ tests for qualitative variables. In all cases, the results were considered statistically significantly when $P$ value less than 0.05 .

\section{Results}

Table 1: Demographic data of our patients.

\begin{tabular}{|c|c|c|}
\hline Variable & Number & \% \\
\hline Age (years)[range] & $53.1 \pm 9.7[40-65]$ & \\
\hline Gender: & 238 & 35 \\
Male (n) & 442 & 65 \\
\hline Female (n) & 508 & 74.7 \\
\hline NYHA functional class & 172 & 25.3 \\
\hline III (n) & 380 & 55.9 \\
\hline IV (n) & 200 & 29.4 \\
\hline Right ventricular hypertrophy (n) & 272 & 40 \\
\hline Edema of lower extremities (n) & 410 & 60.3 \\
\hline Mitral valve pathology: & 170 & 25 \\
Mitral stenosis (n) & 100 & 14.7 \\
\hline $\begin{array}{c}\text { Mitral regurgitation (n) } \\
\text { Mitral stenosis and mitral } \\
\text { regurgitation (n) }\end{array}$ & & \\
\hline
\end{tabular}

The age of our patients ranged between 25-65 years with 
a mean of $54.1 \pm 8.9$ years. $35 \%$ of our patients $(238 / 680)$ were males while $65 \%(442 / 680)$ were females with a male to female ratio $1: 1.9$. In our study, $74.7 \%$ of our patients (508/680) were classified as NYHA class III while $25.3 \%$ (172/680) were classified as class IV. Of our patients $55.9 \%(380 / 680)$ had atrial fibrillation and were under treatment, 272 patients (40\%) had lower limb edema and 200 patients had evidence of right ventricular hypertrophy (29.4\%) (Table 1).

Echocardiographic data revealed that $60.3 \%$ (410/680) of patients had signs of mitral stenosis and 25\% (170/680) had mitral regurgitation while $14.7 \%(100 / 680)$ had double mitral valve pathology (MS and MR). 76 patients (11.2\%) had less than moderate TR, 132 (19.4\%) had moderate TR and 472 (69.4\%) had severe TR. Patients of both groups underwent Echo examination and in group I (severe PHT) PASP ranged between 55-80 mmHg with a mean of $63.5 \pm 18.1 \mathrm{mmHg}$; left atrial diameter (LAD) ranged between $42-63 \mathrm{~mm}$ with a mean of $52.3 \pm 10.3 \mathrm{~mm}$; left ventricular end diastolic diameter (LVDd) ranged between 40 $70 \mathrm{~mm}$ with a mean of $53.1 \pm 8.2 \mathrm{~mm}$ and ejection fraction (EF\%) ranged between $50-65 \%$ with a mean of $56.4 \pm 7.1 \%$. Patients in group II (extreme PHT) PASP ranged between $85-110 \mathrm{mmHg}$ with a mean of $90.3 \pm 10.6 \mathrm{mmHg}$; left atrial diameter ranged between $45-72 \mathrm{~mm}$ with a mean of $56.1 \pm 12.4 \mathrm{~mm}$; left ventricular end diastolic diameter (LVDd) ranged between $55-74 \mathrm{~mm}$ with a mean of $63.3 \pm 9.7 \mathrm{~mm}$ and ejection fraction (EF\%) ranged between 45 $73 \%$ with a mean of $48.4 \pm 6.8 \%$ (Table 2 ).

Table 2: Preoperative and postoperative echocardiographic parameters of 680 patients.

\begin{tabular}{|c|c|c|c|c|c|c|}
\hline \multirow[t]{2}{*}{ Variable } & \multicolumn{3}{|c|}{ Severe PHT } & \multicolumn{3}{|c|}{ Extreme PHT } \\
\hline & Preop & Postop & $\mathbf{P}$ & Preop & Postop & $\mathbf{P}$ \\
\hline PASP (mmHg) & $\begin{array}{c}63.5 \pm 18.1 \\
{[55-80]}\end{array}$ & $\begin{array}{c}42.3 \pm 11.6 \\
{[40-65]}\end{array}$ & 0.001 & $\begin{array}{c}90.3 \pm 10.6 \\
{[85-110]}\end{array}$ & $\begin{array}{c}70.5 \pm 15.2 \\
{[65-95]}\end{array}$ & 0.01 \\
\hline $\mathrm{LAD}(\mathrm{mm})$ & $\begin{array}{c}42.1 \pm 12.3 \\
{[38-55]}\end{array}$ & $\begin{array}{c}39.6 \pm 9.3 \\
{[37-48.1]}\end{array}$ & 0.001 & $\begin{array}{c}51.2 \pm 11.6 \\
{[45-70]}\end{array}$ & $\begin{array}{c}45.1 \pm 10.3 \\
{[37-63]}\end{array}$ & 0.01 \\
\hline LVDd (mm) & $\begin{array}{c}53.1 \pm 8.2 \\
{[40-70]}\end{array}$ & $\begin{array}{c}38.3 \pm 5.1 \\
{[39-63]}\end{array}$ & 0.038 & $\begin{array}{l}63.3 \pm 9.7 \\
{[55-74]}\end{array}$ & $\begin{array}{c}40.3 \pm 5.1 \\
{[39-63]}\end{array}$ & 0.025 \\
\hline LVEF (\%) & $\begin{array}{c}56.4 \pm 7.1 \\
{[50-65]}\end{array}$ & $\begin{array}{c}42.1 \pm 4.1 \\
{[45-78]}\end{array}$ & 0.254 & $\begin{array}{c}48.4 \pm 6.8 \\
{[45-73]}\end{array}$ & $\begin{array}{c}55.7 \pm 5.3 \\
{[45-78]}\end{array}$ & 0.31 \\
\hline
\end{tabular}

PASP: Pulmonary Arterial Systolic Pressure; LAD: Left Atrial Diameter; LVDd: Left Ventricular End-Diastolic Diameter; LVEF: Left Ventricular Ejection Fraction

\section{Operative Data}

Cross clamp time in group I, it ranged between 70-110min with a mean of $85 \pm 9 \mathrm{~min}$ while in group II it ranged between 75 120 min with a mean of $95 \pm 11 \mathrm{~min}$ and the statistical analysis revealed non-significant increase in the cross clamp time in group II $(p=0.211)$. The cumulative perfusion time in group I ranged between $110-140 \mathrm{~min}$ with a mean of $128.5 \pm 11 \mathrm{~min}$ while in group II, the perfusion time ranged between $120-165$ min with a mean of with a mean of $150 \pm 14 \mathrm{~min}$ and the statistical analysis revealed significant increase in the cumulative perfusion time in group II than group I $(\mathrm{p}=0.001)$.
After completion of the surgical procedure and starting to wean from the heart lung machine; we fail to wean only $1.85 \%$ $(10 / 540)$ of cases of group I and $14.3 \%$ (20/140) of patients of group II. We re-established and resumed bypass again, adjust the blood chemistry (electrolytes, gases and $\mathrm{pH}$ ) of patients, ensure connectivity of inotropic support and good ventilation and some patients required getting more fluid out using the hemo-filter due to apparent RV distension and impairment. After reaching a stable hemodynamic condition we start to wean again. The 10 cases of group (I) weaned successfully while 6 cases out of 20 in group (II) failed to wean from bypass and died on table and 14 cases weaned but left open chest due to RV impairment and distension (Table 3).

Table 3: Intra-operative characteristics and post-operative outcomes in pre-operative severe PHT patients, (680 cases).

\begin{tabular}{|c|c|c|c|}
\hline Variable & PAP $50 \leq 80 \mathrm{mmHg}, \mathrm{n}=540$ & PAP $>80 \mathrm{mmHg}, \mathrm{n}=140$ & $\mathbf{P}$ \\
\hline Perfusion time (min) & $128.5 \pm 11(110-140)$ & $150 \pm 14(120-165)$ & 0.001 \\
\hline Cross-clamp time (min) & $85 \pm 9(70-110)$ & $95 \pm 11(75-120)$ & 0.211 \\
\hline Failure to wean & $10(1.58 \%)$ & $20(14.3 \%)$ & 0.01 \\
\hline $\mathrm{PH}$ criss in ICU & $10(1.35 \%)$ & $10(7.14 \%)$ & 0.01 \\
\hline Readmission within 30 days & $40(7.4 \%)$ & $18(12.9 \%)$ & 0.26 \\
\hline 30 days mortality (\%) & $20(3.7 \%)$ & $20(14.3 \%)$ & 0.03 \\
\hline
\end{tabular}

MPAP was found to decrease significantly over time as compared to baseline. Also, PVR decreased over time. 
After weaning, patients admitted to ICU and all were under inoptropic support in the form of pulmonary vasodilator (Milrinone) and Norepinephrine in addition to dobutamine infusion in some cases. All patients were sedated on Fentanyl infusion. And we postponed weaning from mechanical ventilator until patients became hemodynamically stable and avoid pain and stress in order to prevent the rise in pulmonary pressure. We also gave the patients Sildenafil by NGT at a dose of $0.5 \mathrm{mg} /$ kg every 6-8hours according to the hemodynamics. In ICU; ten patient of group I $(10 / 540 ; 1.85 \%)$ and ten patients of group II $(10 / 140 ; 7.14 \%)$ experienced pulmonary hypertensive crisis (severe hypotension and cyanosis), sudden arrest or persistent hemodynamic instability and they managed by cardiac resuscitation with increasing the dose of inotropic support and pulmonary vasodilators, complete sedation and oxygen therapy. The statistical analysis revealed occurrence of this crisis in a large scale in group II $(\mathrm{p}=0.01)$.

Forty patients out of group I $(40 / 540 ; 7.4 \%)$ while 18 patients of group II $(18 / 140 ; 12.9)$ were readmitted to the operative theatre for different cases "bleeding, cardiac tamponade or sternal closure for cases with opened chest" and they were managed according to the cause and the statistical analysis revealed no significance between both groups $(p=0.26)$. Mechanical ventilation hours in group I ranged between 12-76 hours and mean of 28 \pm 0.82 while in group II it ranged between 11-124 hours and mean of $56 \pm 1.3$ and the statistical analysis revealed the increase in mechanical ventilation in group II than in group I $(\mathrm{p}=0.031)$. In group I, 6 cases out of $540(1.1 \%)$ were readmitted to ICU after 2-5 days of ward transfer for cardiac or respiratory failure in addition to 10 cases for cardiac tamponade or pericardial hematoma. In group II; 4 cases out of $140(2.9 \%)$ were readmitted to ICU after 2-5 days of ward transfer for cardiac or respiratory failure and another 4 cases $(2.9 \%)$ for cardiac tamponade or pericardial effusion and 6 (4.3\%) cases for management of rapid AF.

Cumulative ICU stay in days in group I ranged between 2-5 days with a mean of $3 \pm 0.5$ days while in group II it ranged between 4-6 days with a mean of $5.5 \pm 0.5$ days and the statistical analysis revealed increased ICU stay in group II than in group I ( $p=0.028)$ Most of mortality in both groups occurs during the first postoperative week and occurred due to hemodynamic instability and acute heart failure. It was $3.7 \%(20 / 540)$ in group I and $14.3 \%$ $(20 / 140)$ in group II with a marked rise in this rate between patients of group II ( $\mathrm{p}=0.03) .12$ cases out of the $20(60 \%)$ of mortality of group I were above fifty years old and 16 cases out of the 20 cases of mortality of group II (80\%) were above fifty years old and the statistical analysis revealed that increased age with the severity of pulmonary hypertension increase the rate of mortality ( $\mathrm{p}=0.031$ ) (Table 4).

Table 4: Relation between age of the patients and mortality in the study.

\begin{tabular}{|c|c|c|c|}
\hline Age of Patients & PAP $\mathbf{5 0} \leq \mathbf{8 0} \mathbf{m m H g}, \mathbf{n = 2 0}$ & PAP $\mathbf{8 0} \mathbf{m m} \mathbf{H g}, \mathbf{n = 2 0}$ & P \\
\hline Below 50 years & $40 \%(8 / 20)$ & $20 \%(4 / 20)$ & \\
\hline Above 50 years & $60 \%(12 / 20)$ & $80 \%(16 / 20)$ & 0.031 \\
\hline
\end{tabular}

Ten cases out of the $20(50 \%)$ of group I were have severe tricuspid regurgitation while 14 cases out of the 20 cases of group II $(70 \%)$ have severe tricuspid regurgitation and the statistical analysis revealed that with increased severity of tricuspid regurgitation the mortality rate increases in cases with increased pulmonary pressure $(\mathrm{p}=0.028)$. It is important to know that the rate of complications and the mortality rise with the increase in pulmonary pressure up to $90 \mathrm{mmHg}$ (cut-off value) were there was no marked change in these rates.

\section{Follow-up ECHO Examination}

Echocardiographic examination performed in the follow-up period at the end of first week post-operative, one, three and six post operative months. Patients of group I (severe PHT) the statistical analysis revealed that in the early and late follow-up showed marked decrease in the pulmonary artery pressure PASP ranged between $35-65 \mathrm{mmHg}$ with a mean of $42.3 \pm 11.6 \mathrm{mmHg}$ with significant reduction in the PASP $(p=0.001)$. Also, the increased in the period between the diagnosis of the lesion and the time of operative procedure decreased the reverse of the rise in pulmonary pressure. The statistical analysis revealed that in the early follow-up period there was no marked change in Left
Atrial Dimentions (LAD) while in the late follow-up LAD ranged between $37-48.1 \mathrm{~mm}$ with a mean of $39.6 \pm 9.3 \mathrm{~mm}$ with good reduction in $\operatorname{LAD}(\mathrm{p}=0.001)$.

Also, the statistical analysis revealed that in the early followup period there was no marked change in LVDd (left ventricular diastolic dimension) while in the late follow-up LVDd ranged between $32-45 \mathrm{~mm}$ with a mean of $38.3 \pm 5.1 \mathrm{~mm}$ with a significant decrease in the LVDd as a result of reduction in the left ventricular mass ( $\mathrm{p}=0.038)$. In addition, ejection fraction ( $\mathrm{EF} \%$ ) at six months follow-up ranged between $45-78 \%$ with a mean of $42.1 \pm 4.1 \%$ and the statistical analysis revealed no significant change in the EF of group I between preoperative values and the follow-up values even at the end of follow-up (six months, $\mathrm{p}=0.254$ ).

Patients of group II (extreme PHT) the statistical analysis revealed that in the early follow-up period there was also significant decrease in PASP in comparison to the preoperative measurements but with severe hypertension in many cases where PASP ranged between $45-78 \mathrm{mmHg}$ with mean of $62 \pm 10 \mathrm{mmHg}$ while in the 6-month follow-up PASP ranged between 40$70 \mathrm{mmHg}$ with mean of $55 \pm 8 \mathrm{mmHg}$ with significant reduction in the PASP $(p=0.01)$. The statistical analysis revealed that in the 
early follow-up period there was no marked change in LAD while in the late follow-up LAD ranged between $37-63 \mathrm{~mm}$ with a mean of 39.6 $\pm 9.3 \mathrm{~mm}$ with significant reduction in the LAD ( $\mathrm{p}=0.01)$.

Also, the statistical analysis revealed that in the early followup period there was no marked change in LVDd while in the late follow-up LVDd ranged between $39-63 \mathrm{~mm}$ with a mean of $40.3 \pm 6.3 \mathrm{~mm}$ with a significant decrease in the LVDd as a result of reduction in the left ventricular mass $(p=0.025)$. As well as, ejection fraction $(\mathrm{EF} \%)$ at six months follow-up ranged between $45-78 \%$ with a mean of $55.7 \pm 5.3 \%$ and the statistical analysis revealed no significant change in the ejection fraction of group I between preoperative values and the follow-up values even at the end of follow-up (six months, $\mathrm{p}=0.31$ ).

\section{Discussion}

Pulmonary arterial hypertension, defined as a mean pulmonary arterial pressure greater than $25 \mathrm{mmHg}$ at rest or greater than $30 \mathrm{mmHg}$ during exercise [12]. According to this definition, all our patients in this study have pulmonary hypertension at presentation. Throughout the 40 years over which surgical correction has been carried out, peri-operative mortality in mitral valve surgeries has decreased from $12.5 \%$ in the late 1950 s to $6 \%$ in the 1960 s, and to below $0.5 \%$ today. This major improvement in survival appears to be a reflection of both better operative technique and better post-operative care.

Some studies demonstrated in their work, $10 \%$ to $41.8 \%$ of patients developed pulmonary hypertension with mitral valve disease in varying degrees. Also, an interesting reference in the work of some authors, who demonstrated that in a number of patients with rheumatic mitral valve disease even with severe hypertension pre-operatively, had a good post-operative course, and found no relationship between pulmonary pressures preoperatively. Enter [9] and his colleagues in their study have observed comparable outcomes between patients who have severe PHT and those without evidence of PHT and their results suggested that the degree of PHT may be an important consideration when calculating risk for postoperative mortality.

Recent series suggest that PHT should be included in the STS risk score [13]. However, in multivariate analyses, potential confounders (e.g., chronic obstructive pulmonary disorder) in PHT patients undergoing MVS may have exaggerated the mortality risk [14]. Ghoreishi et al. [15] reported a hospital mortality of $12 \%$ in patients underwent mitral valve surgery with severe PHT and they concluded that referral for MVS should be considered for patients who have PASP $40 \mathrm{~mm} \mathrm{Hg}$ or more lead to increased surgical risk.

Galie et al. [16], investigate the use of Phosphodiesterase type 5 inhibitors in PAH include sildenafil, tadalafil, and vardenafil. These agents have been shown in clinical trials to improve six-minute walk distance and hemodynamics. In our study, sildenafil was given as a routine medication for all cases with high pulmonary artery pressure; we found $66 \%$ of the total cases to have no significant reduction in PAP before taking surgical repair. In literatures concerned about sildenafil found that, mid-term oral sildenafil therapy led to insignificant improvement in pulmonary hemodynamics, functional class and/or exercise tolerance $[17,18]$. So, in our study we assumed that there was insignificant reduction in post operative PASP with the use of pre and postoperative sildenafil and we think that the surgical correction alone is the main factor in reduction of postoperative PASP.

Age also was found to be a significant and independent predictor of surgical mortality and morbidity at early, mid and late follow up in our group of patients as same as other studies done by Simonneau et al. [12]. Secondary prophylaxis has been proved to be cost-effective and practical even in the poorest countries. For more than 20 years, the World Health Organization has recommended secondary prophylaxis, most effectively delivered within a coordinated program using a registry of patients, as the first priority for the control of rheumatic heart disease. Yet most developing countries still do not have effective secondaryprophylaxis programs [19-23].

\section{Conclusion}

Mitral valve replacement (MVR) with severe PHT could be done with less risk when surgery offered at proper time with management strategy to avoid pulmonary hypertensive events.

\section{Recommendation}

We recommend Surgery should be performed in the younger patient and probably before structural changes in the myocardium or pulmonary vasculature have occured. Early referral of cases of mitral valve disease with PHT to surgery once indicated to avoid increased operative risk secondary to long standing PHT. In addition; the administration of milrinone as a pulmonary vasodilator from the start of surgical procedure as well as during ICU stays in cases of severe and extreme PHT. Also, administration of sildenafil preoperatively and continued postoperatively for six months orally in cases of severe and extreme PHT.

\section{Acknowledgement}

The authors would like to acknowledge all the medical and nursing staff who has contributed to the data collection. Also we would like to thank cardiac surgeons and cardiologists who contributed in patients' management and we would like to thanks the research center's staff for their contribution to this research and for their assistance with revising, and their contribution to conception, design and processing of this project.

\section{References}

1. Carapetis JR (2007) Rheumatic heart disease in developing countries. N Engl J Med 357(5): 439-441.

2. Vachiéry JL, Adir Y, Barberà JA, Champion H, Coghlan JG, et al. (2013) Pulmonary hypertension due to left heart diseases. J Am Coll Cardiol 62(25): D100-D108. 
3. Maeder MT, Schoch OD, Kleiner R, Joerg L, Weilenmann D (2017) Pulmonary hypertension associated with left-sided heart disease. Swiss Med Wkly 147: w14395-w14407.

4. Fang JC, DeMarco T, Givertz MM, Borlaug BA, Lewis GD, et al. (2012) World health organization pulmonary hypertension group 2: pulmonary hypertension due to left heart disease in the adult-a summary statement from the pulmonary hypertension council of the international society for heart and lung transplantation. J Heart Lung Transplant 31(9): 913-933.

5. Pellegrini P, Rossi A, Pasotti M, Raineri C, Cicoira M, et al. (2014) Prognostic relevance of pulmonary arterial compliance in patients with chronic heart failure. Chest 145(5): 1064-1070.

6. Kaple RK, Horn EM (2015) Pulmonary hypertension due to valvular heart disease: Aortic and Mitral. Adv Pul Hypert 14(2): 95-101.

7. Barbieri A, Bursi F, Grigioni F, Tribouilloy C, Avierinos JF, et al. (2011) Prognostic and therapeutic implications of pulmonary hypertension complicating degenerative mitral regurgitation due to flail leaflet: a multicenter long-term international study. Eur Heart J 32(6): 751-759.

8. Nishimura RA, Otto CM, Bonow RO, Carabello BA, Erwin JP, et al (2014) 2014 AHA/ACC guideline for the management of patients with valvular heart disease: a report of the American College of Cardiology/ American Heart Association Task Force on Practice Guidelines. Thorac Cardiovasc Surg 129(23): 2440-2492.

9. Enter DH, Zaki A, Duncan BF, Kruse J, Andrei A, et al. (2016) A contemporary analysis of pulmonary hypertension in patients undergoing mitral valve surgery: Is this a risk factor? J Thorac Cardiovasc Surg 151(5): 1288-1299.

10. Vahanian A, Alfieri O, Andreotti F, Antunes MJ, Barón-Esquivias G, et al. (2012) Guidelines on the management of valvular heart disease (version 2012): the Joint Task Force on the Management of Valvular Heart Disease of the European Society of Cardiology (ESC) and the European Association for Cardio-Thoracic Surgery (EACTS). Eur J Cardiothorac Surg 42(4): S1-S44.

11. Yancy CW, Jessup M, Bozkurt B, Butler J, Casey DE, et al. (2013) 2013 ACCF /AHA guideline for the management of heart failure: a report of the American College of Cardiology Foundation/American Heart Association Task Force on practice guidelines. Circulation 128(16): e240-e327.

12. Simonneau G, Robbins IM, Beghetti M, Channick RN, Delcroix M, et al. (2009) Updated clinical classification of pulmonary hypertension. J Am
Coll Cardiol 54(1): S43-S54.

13. Kennedy JL, LaPar DJ, Kern JA, Kron IL, Bergin JD, et al. (2013) Does the society of thoracic surgeons risk score accurately predict operative mortality for patients with pulmonary hypertension? J Thorac Cardiovasc Surg 146(3): 631-637.

14. Chan V, Ahrari A, Ruel M, Elmistekawy E, Hynes M, et al. (2014): Perioperative deaths after mitral valve operations may be overestimated by contemporary risk models. Ann Thorac Surg 98(2): 605-610.

15. Ghoreishi M, Evans CF, DeFilippi CR, Hobbs G, Young CA, et al. (2011) Pulmonary hypertension adversely affects short- and long term survival after mitral valve operation for mitral regurgitation: implications for timing of surgery. J Thorac Cardiovasc Surg 142(6): 1439-1452.

16. Galiè N, Humbert M, Vachiery JL, Gibbs S, Lang I, et al. (2016) 2015 ESC/ERS guidelines for the diagnosis and treatment of pulmonary hypertension. Rev Esp Cardiol 37(1): 67-119.

17. Choudhary SK, Talwar S, Airan B (2016) Choice of prosthetic heart valve in a developing country. Heart Asia 8(1): 65-72.

18. Toor D, Sharma N (2017) T cell subsets: an integral component in pathogenesis of rheumatic heart disease. Immunol Res doi: 10.1007/ s12026-017-8978-z.

19. Chiang YP, Chikwe J, Moskowitz AJ, Itagaki S, Adams DH, et al. (2014) Survival and long-term outcomes following bioprosthetic vs mechanical aortic valve replacement in patients aged 50 to 69 years. JAMA 312(13): 1323-1329.

20. Rahimtoola SH (2010) Choice of prosthetic heart valve in adults an update. J Am Coll Cardiol 55(22): 2413-2426.

21. Chan V, Lam BK, Rubens FD, Hendry P, Masters R, et al. (2012) Longterm evaluation of biological versus mechanical prosthesis use at reoperative aortic valve replacement. J Thorac Cardiovasc Surg 144(1): 146-151.

22. Musuku J, Lungu JC, Machila E, Jones C, Colin L (2017) Epidemiology of pharyngitis as reported by Zambian school children and their families: implications for demand-side interventions to prevent rheumatic heart disease. BMC Infect Dis 17(1): 473.

23. Huang G, Rahimtoola SH (2011) Prosthetic heart valve. Circulation 123(22): 2602-2605

Your next submission with Juniper Publishers
will reach you the below assets
- Quality Editorial service
- Swift Peer Review
- Reprints availability
- E-prints Service
- Manuscript Podcast for convenient understanding
- Global attainment for your research
- Manuscript accessibility in different formats
( Pdf, E-pub, Full Text, Audio)
- Unceasing customer service
Track the below URL for one-step submission
https://juniperpublishers.com/online-submission.php

